Figure. Adjusted Mean Change from Baseline in DAS28 (CRP) at Weeks 26, 52 and 104 by Patient Type Cohort 1 (seropositive, erosive early RA)

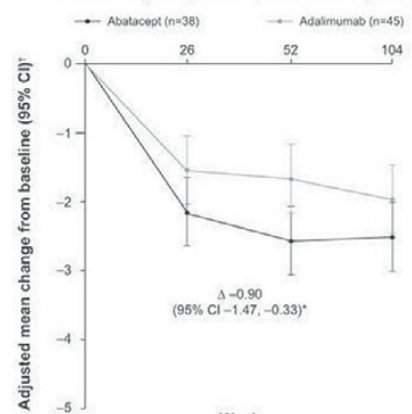

Week

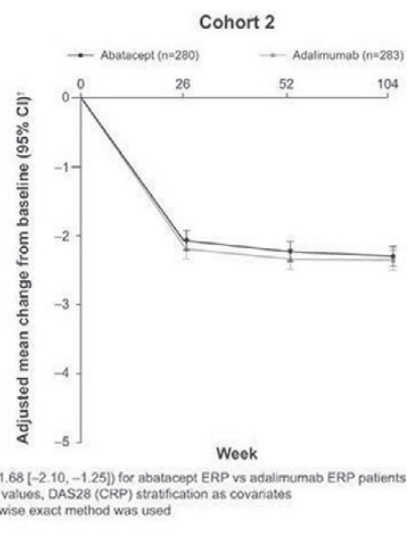

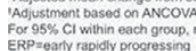

[2] Aletaha D, et al. Arthritis Rheum 2010;62:2569-81.

[3] Weinblatt M, et al. Arthritis Rheum 2013;65:28-38.

Disclosure of Interest: R. Fleischmann Grant/research support from: AbbVie, Amgen, Astellas, AstraZeneca, Bristol-Myers Squibb, Celgene, Janssen, Eli Lilly, Merck, Novartis, Pfizer, Roche, sanofi-aventis, UCB, Consultant for: AbbVie, Amgen, AstraZeneca, Bristol-Myers Squibb, Celgene, Janssen, Eli Lilly, Pfizer, Roche, sanofi-aventis, UCB, M. Weinblatt Grant/research support from: Amgen, Bristol-Myers Squibb, Crescendo Bioscience, UCB, DxTerity, Consultant for: Amgen, Bristol-Myers Squibb, Crescendo Bioscience, UCB, AbbVie, Lilly, Pfizer, Roche, H. Ahmad Shareholder of: Bristol-Myers Squibb, Employee of: BristolMyers Squibb, M. Maldonado Shareholder of: Bristol-Myers Squibb, Employee of: Bristol-Myers Squibb, E. Alemao Shareholder of: Bristol-Myers Squibb, Employee of: Bristol-Myers Squibb, J. Ye Shareholder of: Bristol-Myers Squibb, Employee of: Bristol-Myers Squibb, M. Schiff Consultant for: AbbVie, Bristol-Myers Squibb, Eli Lilly, JNJ, UCB, Speakers bureau: AbbVie

DOI: 10.1136/annrheumdis-2017-eular.3521

\section{SAT0042 SEVERITY OF RADIOGRAPHIC DESTRUCTION ON PERIPHERAL JOINTS IS A STRONG INDEPENDENT RISK FACTOR FOR CAROTID ATHEROSCLEROSIS}

J.S. Eun, E.S. Lee, J.W. Kang, J.H. Kim, J.Y. Kang, G.B. Bae, N.R. Kim, S.J. Lee, E.J. Nam, Y.M. Kang. Kyungpook National University School of Medicine, Daegu, Korea, Republic Of

Background: In our previous study, we identified that cumulative inflammatory burdern contributes to the development of carotid atherosclerosis through a synergistic interaction with conventional cardiovascular (CV) risk factors in patients with rheumatoid arthritis (RA). However, it is controversial whether the presence of joint destruction which result from inflammatory burden may be a risk factor for carotid atherosclerosis.

Objectives: To investigate whether intima-media thickness (IMT) and plaques of carotid artery are influenced by radiographic joint destruction in patients with RA. Methods: A total of 186 patients with RA were included in the present study. Plain X-ray of joints were used to assess the severity of joint destruction. We developed a new radiographic scoring system, named Rheumatoid Arthritis-Radiographic Severity Score (RA-RSS), which scores 21 joint groups with the modified Steinbrocker method. The following joint groups were included: 2 proximal interphalangeal (PIP) joint group, 2 metacarpophalangeal (MCP) joint group, 2 wrist joint group, 2 elbow joint group, 2 shoulder joint group, 1 atlantoaxial joint group, 2 hip joint group, 2 knee joint group, 2 ankle joint group, 2 tarsometatarsal (TMT) joint group, and 2 metatarsophalangeal (MTP) joint group. The grade was determined by the worst changes in each joint group of PIP, MCP, TMT, and MTP joints. RA-RSS grades are assigned as follows: 0 = No radiographic changes; 1 $=$ mild destruction of bone and cartilage; 2 = moderate destruction of bone and cartilage or joint deformities; 3 = Severe destruction of bone and cartilage or bony ankylosis (Score ranges from 0-63). We performed carotid ultrasound to detect the presence of carotid atherosclerosis.

Results: Among 186 patients who were graded using RA-RSS, 110 patients had carotid plaques (59.1\%). RA-RSS was significantly higher in patients with plaques compared to patients without plaques (11.2 \pm 8.79 vs. $7.6 \pm 7.72, p=0.004)$. Patients were divided into two groups by the cut-off value of plaque development as determined using receiver operating characteristic (ROC) curves: $115(61.8 \%)$ patients with RA-RSS $<10$ and $71(38.2 \%)$ with RA-RSS $\geq 10$. There was a significant difference between the groups with respect to the presence of plaques $(48.7 \%$ vs. $76.1 \%, p<0.001)$, while there was no difference in mean carotid IMT $(0.87 \pm 0.19$ vs. $0.88 \pm 0.14, p=0.684)$. The mean age, the presence of conventional $\mathrm{CV}$ risk factors, Korean version of the modified HAQ (mKHAQ), DAS28-ESR, and RA-RSS $\geq 10$ were significantly associated with plaque development. Multivariate logistic regression analysis showed that RA-RSS $>10$ (OR $2.94[95 \% \mathrm{Cl} 1.48-$ 5.84]) and the presence of conventional CV risk factors (OR $2.30[95 \% \mathrm{Cl}$ $1.21-4.35])$ were independent risk factors for plaque development.
Conclusions: The present study shows that radiographic destruction over peripheral joints, which directly reflects cumulative inflammatory burden, is a strong independent risk factor for plaque development that is associated with CV events and mortality.

References:

[1] Churl Hyun Im, et al. Inflammatory burden interacts with conventional cardiovascular risk factors for carotid plaque formation in rheumatoid arthritis. Rheumatology (Oxford). 2015 May;54(5):808-15.

Disclosure of Interest: None declared

DOI: 10.1136/annrheumdis-2017-eular.5985

\section{SAT0043 FACTORS AFFECTING THE NEED FOR ORTHOPAEDIC SURGERY IN PATIENTS WITH RHEUMATOID ARTHRITIS. RESULTS FROM 1010 PATIENTS DIAGNOSED WITH RA FROM 1972-2009}

B.-T.S. Fevang ${ }^{1,2}$, A.M. Fenstad ${ }^{3}$, O.N. Furnes ${ }^{3,4}$, T.W. Nystad ${ }^{1,3} .{ }^{1}$ Dept. of Rheumatology, Haukeland University Hospital; ${ }^{2}$ Dept. of Clinical Sciences, University of Bergen; ${ }^{3}$ The Norwegian Arthroplasty Register, Haukeland University Hospital; ${ }^{4}$ Department of Surgical Sciences, University of Bergen, Bergen, Norway

Background: Surgery still comprises a necessary part of treating RA patients, when medication fail to prevent joint destruction. Orthopaedic corrective procedures are considered a reliable and objective proxy for a destructed joint, and is an important outcome measure in RA.

Objectives: To investigate how patient characteristics, time of diagnosis and treatment affect the need for orthopaedic surgery in patients with rheumatoid arthritis (RA).

Methods: We reviewed the medical history of 1544 patients diagnosed with RA at Haukeland University Hospital in Bergen, Norway from 1972 to 2009, of which 1010 (mean age 57, 69\% women) were included in the study. Relevant orthopaedic procedures were obtained from the Norwegian Arthroplasty Register and the hospital's administrative patient records. 693 procedures (joint synovectomies $22 \%$, arthrodeses $21 \%$, prostheses $41 \%$ and forefoot procedures $12 \%$ ) were performed in 315 patients. Survival analyses were completed to evaluate the impact of age, sex, radiographic changes and year of diagnosis, on the risk of undergoing surgery.

Results: Patients diagnosed in 1972-1985 and 1986-1998 had a relative risk (RR) of 2.4 and $2.2(p<0.001)$ respectively, of surgery compared to patients diagnosed in 1999-2009. Radiographic changes at diagnosis and female sex were also significant risk factors. Disease activity at baseline did not affect the outcome. Anti-rheumatic medication was significantly different in the three time periods.

\begin{tabular}{lccccc}
\hline Variable category & 5 years $^{\mathrm{a}}$ & 10 years $^{\mathrm{a}}$ & $\mathrm{RR}$ & $95 \% \mathrm{Cl}$ & $\mathrm{p}$-value \\
\hline Gender, male & 13 & 22 & 1 & & \\
female & 19 & 30 & 1.35 & $1.02-1.77$ & 0.035 \\
Age (years) & & & & & \\
$\quad<69$ & 15 & 27 & 1 & & \\
$\quad 22$ & 31 & 1.04 & $0.77-1.42$ & 0.78 \\
$\quad$ Radiolographic changes at diagnosis & & & & & \\
$\quad$ No arthritis & 12 & 21 & 1 & & \\
$\quad$ Possible arthritis, or MR findings only & 19 & 26 & 1.01 & $0.66-1.57$ & 0.92 \\
$\quad$ Arthritis & 23 & 34 & 1.46 & $1.10-1.94$ & 0.008 \\
$\quad$ Osteoarthritis & 35 & 55 & 2.81 & $1.94-4.05$ & $<0.001$ \\
Time period & & & & & \\
$\quad 1999-2009$ & 12 & 18 & 1 & & \\
$\quad 1986-1998$ & 25 & 38 & 2.16 & $1.62-2.87$ & $<0.001$ \\
$\quad 1972-1985$ & 15 & 37 & 2.38 & $1.71-3.31$ & $<0.001$
\end{tabular}

a- and 10-year survival, in percent.

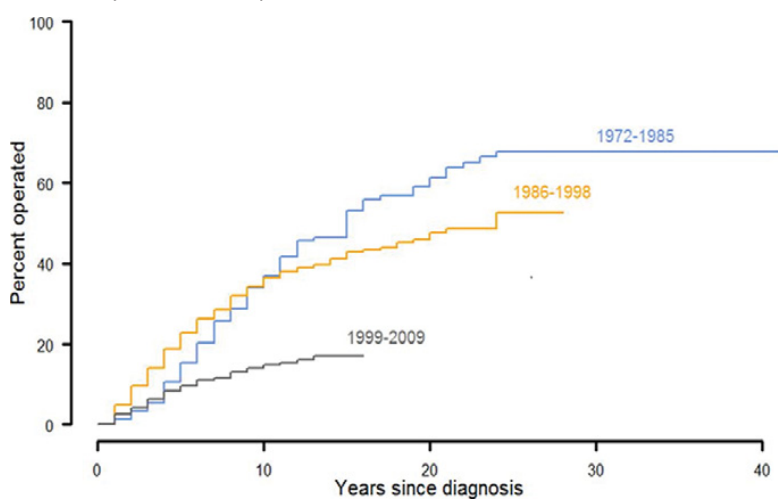

Conclusions: Patients with early years of diagnosis had greatly increased risk of having an RA related procedure performed. This is probably due to the year of diagnosis being a proxy for the type and intensity of medical treatment.

References:

[1] Goodman SM. Rheumatoid Arthritis Therapy and Joint-replacement Surgery: Are We Making a Difference? J Rheumatol. 2016;43:833-5. 